\title{
ESCAPE ROOM AS A MOTIVATING TOOL IN THE ENGLISH LITERATURE CLASSROOM AT TERTIARY EDUCATION
}

\author{
Madalina Armie, José Francisco Fernández Sánchez, \& Verónica Membrive Pérez \\ Department of English Studies, University of Almería (Spain)
}

\begin{abstract}
The escape room, also known as escape game, is a gamification tool that aims to promote increased motivation and improved teamwork (Wood \& Reiners, 2012). Recently, escape rooms have achieved prominence in the classroom as pedagogical instruments valid for any type of discipline. In the educational field in particular, the escape room can be defined as an action game in real time where the players, in teams, solve a series of puzzles or problems and carry out tasks related to the curricular contents worked on throughout the course, in one or more rooms with a specific objective and at a specific time (Nicholson, 2015). To do this, learners must put into practice the knowledge acquired about a particular subject, as well as their creative and intellectual abilities, and deductive reasoning. Despite being a pedagogical tool that has emerged as an innovative element in the last five years or so, the use of escape rooms for teaching-learning the English language at different educational levels has been studied qualitatively and quantitatively (Dorado Escribano, 2019; López Secanell \& Ortega Torres, 2020). However, there is no study on the applicability of the escape room in the English literature classroom at the tertiary educational level. This paper aims to demonstrate how the inclusion of this innovative pedagogical tool can serve not only for teaching the language, but also for working on theoretical-practical contents of subjects focused on literary studies of the Degree in English Studies. In order to achieve the proposed objectives, the study will focus on the identification of types of exercises to implement as part of the educational escape room aimed at a sample of students; the preparation of tests/ exercises based on the established objectives; the design of a pre- and a post- questionnaire based on the established objectives; the implementation of the escape room in the literature class and the evaluation of the impact of this educational tool to foster students' motivation.
\end{abstract}

Keywords: Escape room, new technologies, intrinsic motivation, English literature, higher education.

\section{Introduction}

The reason for presenting this paper has to do with the need felt by a group of lecturers of literature in English, an area of knowledge normally labelled under the general term of 'English Literature', to engage their students with the subjects of their respective courses at university level. The teaching of literature has traditionally been at the mercy of to two kinds of pressures, those that push the discipline towards the implementation of scientific methods, and those which celebrate the multifarious concerns that are normally associated with the idea of reading for pleasure. It is the second aspect, the natural tendency of literature towards interdisciplinarity, that has traditionally been uppermost in the daily practice of this activity: "One of the reasons for this is that literature is about everything - love, sex, friendship, family relationships, aging, death, social and historical change, religious faith, intellectual ideas, and so on. In short, it is about life in all its diversity, and this is hard to accommodate within the narrow parameters of a discipline" (Moran 2002: 21). The present proposal, however, starts from the assumption that it is possible to celebrate literature's extraordinary transversality of interests and, at the same time, to carefully design and implement activities for the teaching of the subject which take into account academically-tested methods and scientifically-oriented perspectives.

The framework of gamification has been chosen because it is "an emerging approach and tool for teaching [which] provides the opportunity to create new, challenging, meaningful and interactive learning experiences for today's students" (Santamaría and Alcalde 2019: 84). The main concern as educators is to keep abreast professionally and, therefore, to apply in our courses recent theories related to motivation, not because of a superficial need to stay in tune with the times, but because students in the 21 st century demand new perspectives on education that participate in the technological world in which they live. 
Motivation in the literature class, on the other hand, just as it happens in the foreign language class, is far from being an easily packed and digested concept. Lecturers of literature are aware of the multiple factors (cognitive, socio-cultural, psychological, etc.) that have to be considered when designing a course: "Motivation has long been a hot topic in educational research because of its complexity. The construct of motivation is not a single entity but a multi-factorial one" (Wong 2014: 38). The aim of this paper is to explore one of the most successful developments of gamification, namely, the use of escape rooms in class as a motivational tool, and to apply it to the teaching of English literature. A succession of challenges and a diverse assortment of activities may raise the interest of students and increase their engagement with the dynamics of the course.

\section{Escaping boredom in the classroom: Advantages and disadvantages}

The origins of escape rooms are somehow diffuse, although research (Gómez Sesé 2020) considers 2007 as a point of inflexion in the historical development of this form of entertainment and edutainment. In 2007, the Japanese movie and anime director Takao Kato hosts in Kyoto the Real Escape Game (REG), and shortly afterwards, a big game named HEP Hall in Osaka. These events that are soon followed by the creation of a digital magazine by Kato under the name Real Escape Games, where the concepts and ideas behind this gamified experience are laid bare. Considering these first successes, numerous rooms are opened in Singapore in 2011, and only one year later, the escape room concept becomes famous in San Francisco with the "Puzzle Break" project. At the same time and in Europe, the first escape room is opened in Budapest by Attila Gyurkovics the founder of the franchise Parapark (Gómez Sesé 2020: 33). By 2019, there were over 7,200 escape rooms in 1,445 cities in 105 countries (Kroski, 2019, p. 3), and their numbers keep rising every day, offering fun and enjoyment to people of all ages with missions as diverse as saving the world, travelling to Mars, escaping zombies, getting out of a medieval castle or a haunted mansion, breaking out of a prison, time travels etc.

Definitely, the field of escape rooms is one in expansion due to the infinite number of possibilities which it offers, especially when included in the educational curriculum. Learning is inherent to games, as intrinsic motivation is triggered, and deep knowledge is consolidated through playing which is always a desirable experience. Students' motivation is one of the major quandaries for education and research nowadays, no matter the educational level under consideration, with many studies emphasizing the obsolescence of the teacher-centered approach and that of the ineffectiveness of the overreliance on traditional forms of delivering content in class (Lee \& Hammer, 2011). These studies draw a concluding connection between intrinsic motivation and problems of levels cheating, disengagement from school, and with this, higher attrition rates, while proposing gamification as a possible panacea (Cronk, 2012; Deterding, 2012; Stott and Neustaedter, 2013). Frequently along sessions, educators can observe their distracted students checking the time, looking at their watches or their mobile phones hopelessly and impatiently. This might be a clear sign of boredom, distraction, and an open manifesto of our pupils' enormous desire to escape the class as soon as possible. Nonetheless, terms can be shifted, and students can check the time for a totally different reason: they do not want the class to be over; they want to remain there trapped until they have successfully concluded their class activity. Time limits and space confinements are only two of the key elements in escape room games, and by extension educational escape rooms which foment motivation and widen the universe of learning.

Escape rooms have evolved despite their short historical existence and have adapted themselves perfectly to the vicissitudes of the current pandemic situation, to the extent that it has become totally feasible to create and play an escape room totally online. What is more, the use of the ICT dimension in the elaboration of a hybrid version of this form of gamification - which might combine physical and virtual resources - help to diversify and enrich the players' experience. As a matter of fact, curiously and contrary to what is expected, it was the virtual version - where "an avatar in a specific setting, interacting with various objects to uncover clues and using information from those clues to solve puzzles" (Brainy Rantz 2017) - the precursor for the live and physical experiences offered by escape rooms nowadays worldwide.

Escape rooms can be designed around any subject or around many transversal contents of diverse disciplines such as mathematics, chemistry, history, etc, providing dynamism to the lessons and to content which might not be very appealing to students. Educational escape rooms, therefore, are conceptualized as bridges between reality and adventure (Kato, n.d.), knitted systems, where all the elements form a complex whole. The gamified experience, then, is not a single element but an entire context, where knowledge is placed at the very centre. Nonetheless, the success of a game in the classroom depends not only on external factors to the students, such as the difficulty of the game, its regularizing system of rewards and punishments, its didactic objectives, its duration, the props used to recreate the thematic atmosphere of the game etc., but also on internal factors related to the players 
themselves, as their motivations, perspectives, and tastes. Considering their nature, escape room games are closed systems that engage players in a well-planned structure, but which might present unequal and uncertain outcomes. The maintenance of high levels of motivation and engagement along the experience is drawn from equilibrated doses of difficulty and challenge offered by the game. The design of an escape room is not exactly and easy process, but one that requires knowledge in the different fields ranging from the arts, psychology to computer science, and which follows basic steps marked by literature and experimentation that stress the importance of a careful selection of the thematic, the conceptualization of the idea to be carried out into practice, the design of the mechanics of the game, the cycle for the development of the game and the establishment of the elements to be included, among others. In relation to all these ideas, one of the most important pieces for the assembling of an escape room experience carried out in the classroom is the drawing of a connection between the game and the non-ludic or didactic objective; that is, the game must present a balance between what is known as edutainment and game, without forgetting the major aim of this educational tool: the didactic side of the experience.

This dynamic method based on escape room experiences might be used either as a reinforcement activity or as an evaluation tool, and it can last for only one session, for days, or even an entire school year, a process along which the student plays an active role in the leaning process. With the implementation of escape rooms, the boredom provoked by conventional exercises is fought with novelty, and although pressure exists, this is a totally different experience to the one infused by traditional exams. Here the existence and perception of pressure is constructive, as the urgency to solve the challenges helps students to focus on a scenario where every second counts; however, students do not feel alone facing the mission or the trouble. While promoting the development of personal qualities such as persistence and resilience through extended play (McGonigal, 2011), the student is part of a mechanism, of a team that works together, which puts knowledge together, unfolding students' deductive thinking, and attempting to overcome challenges by calibrating and discussing decisions. Individual creativity, resourcefulness, and good communication skills mark the difference when managing to solve each task collectively, therefore the application of this form of gamification in class foments negotiation and collaboration. The improvement of self-awareness, strategizing, and the triggering of critical capacities to make decisions or to adopt a position of leadership are also learnt. These interpersonal or social abilities stimulate the strengthening of relationships among players, facts that on long term can be beneficial for the development of lessons and other group activities, as they create a positive atmosphere among peers and improve class management and dynamics. In relation to gamification in the literature class at university level, apart from all these mentioned aspects, escape room and by extension gamification promote the assimilation of new vocabulary and grammar (Abrams \& Walsh, 2014), and improve oral communication, as oral skills are used along the entire experience for communication and negotiation of decisions. Written comprehension and production much present in the challenges (Mazur, Rzepka \& Araki, 2011; Grouling, Hedge \& Schweigert, 2014) are strengthened.

As regards the disadvantages of this innovative instrument and gamification tool, these are common to the pitfalls of the methodology of gamification in general. It is worth here mentioning the great amount of time which must be invested for the creation of an escape room that might mirror the class's necessities, objectives, and contents. However, despite being time consuming and tedious, this educative instrument can be easily later adapted to different educative levels. Also the implementation of escape room experiences might not be totally satisfactorily, especially following the online format due to possible technological problems. The escape room might also become an unmanageable activity when considering the numerous groups and the high number of students in each university class. In this case, the lecturer might need help from other colleagues in order to carry out the experience. The present article, nonetheless, considers that the disadvantages of escape rooms fall short in comparison to the benefits offered by this valuable form of edutainment with so many positive side effects as the following pages are going to reveal.

\section{Results}

After assessing the applicability of Escape Rooms to education and the advantages and disadvantages of their use in the classroom as an educational tool, especially in the English classroom, the experimental session was carried out. This experience was aimed at adding extra value to regular sessions on English literature, with the purpose of evaluating an improvement of students' active participation, teamwork and engagement regarding the course contents both theoretical and practical. What is more, the function of Escape Rooms in an English literature classroom is an innovative approach to the pedagogical dynamics of Escape Rooms since, as it has been explained, there is no scientific evidence to this point that this kind of resource has been used before as an educational instrument. Since this experiment was carried out in 2020 and tertiary education sessions were taught online due to the emergency derived from 
Covid-19, the Escape Room experience was designed to be developed online by educators/facilitators and, by extension, students too. This implied a great adaptability to educators' training requirements and usefulness as well as students' interest which allowed us to explore the effectiveness of a combination of gamification and IT tools in the English literature (virtual) classroom.

The study aims at analyzing, qualitatively and quantitatively, the degree of motivation before and after the implementation of the Escape Room when compared to conventional teaching methods. The sample group for this intervention was composed of 29 undergraduate students (19 to 27 years old, 85,2 $\%$ female and $14,8 \%$ male) who have taken any courses on English Literature (second or third year) as part of their regular academic load in a Spanish university. The experiential cluster was selected because of its accessibility for the researchers and because of a considerable number of newly arrived students who were not motivated. The experiment took place once at the end of the semester with a length of approximately 3 hours each to solve the virtual Escape Room with the intention of reviewing the main contents taught for 16 weeks. Spoken and written production and comprehension were part of the daily schedule and proposed activities. The first half an hour of the intervention was devoted to eliciting the Escape Room regulations and functionality and to solve questions.

The designed Escape Room consisted of six challenges, each of them only accessible progressively after a suitable completion. All challenges were set in the historical context of the authors included in the syllabus of the corresponding course on English Literature and related to texts and genres dealt with throughout the semester. The challenges included a variety of activities such as puzzles, padlocks, audiovisual resources, or the use of (simulated) social networks and participants were aimed not only at searching for answers on the course materials (which allowed participants to properly review course contents) but also to extend their knowledge by looking for information from other sources (websites, audiovisual contents, books, and articles).

Before the experiment, all participants filled out a survey composed by 24 close-ended questions on a 1-5 scale to investigate students' motivational approach and enthusiasm towards English Literature lessons at a tertiary level and traditional and current teaching methodologies. Besides, they were also asked to identify their observations regarding cooperation and competition in learning, teamwork and working on online assignments. Finally, students had to expose their degree of interest in gamification as a tool to learn English Literature. Similarly, a post-intervention survey composed by 15 close-ended questions on a 1-5 scale was designed to assess the impact of the tool on the students' acquisition and learning process, insisting upon the degree of stimulation and significance of the content of the activities, the usability of the tool after the experiment and whether or not students would recommend this teaching practice to acquire contents related to English Literature.

Results from the survey before the intervention expose that a 70,4\% participants consider that learning English Literature is useful and a $63 \%$ believe that its acquisition is difficult. General participation in activities done in the classroom is average (a 55,5\% participants chose 4 or 5 out of 5) and a 70,3\% claim to work hard to acquire the required knowledge to pass the course. However, even if a $37 \%$ enjoy attending English literature classes and that a 48,1\% feel the need to learn more because they like the contents, one of the key questions related to engagement reveals that only a $18,5 \%$ participants feel motivated in English Literature lessons and only a 14,8\% are willing to participate actively. Besides, $85,2 \%$ of students admit that their motivation depends on the professor teaching the course. Regarding questions related to gamification as a pedagogical tool, all participants (100\%) believe that learning through games is useful to strengthen their knowledge related to course contents and that they prefer games than traditional learning styles (63\%).

The post-experiment survey focuses on questions related to the Escape Room experience carried out virtually and its impact on students' motivation when learning English Literature. Most participants considered that learning English Literature through escape rooms was useful $(89,7 \%)$ and easier $(89,6 \%)$. Besides, the experience done in the virtual classroom was very successful since a $96,6 \%$ declared to have enjoyed their active participation. The experiment seemed to have impacted respondents' attitude towards English Literature classes as an $89,7 \%$ claimed to show a more positive approach towards contents and activities if Escape Rooms are part of the teaching methods used in the classroom and considered that the professor would motivate them $(93,1 \%)$ when Escape Rooms are included an assessment method. Finally, learning through games such as this one would be beneficial for students' acquisition (89,7\%) and it was preferred by a $96,5 \%$ participants to traditional learning styles. According to the results delivered by respondents' answers, the Escape Room as a pedagogical tool seems to confirm to be a particularly beneficial and motivating resource to teach English literature and to have a strong impact on students' approach to contents. 


\section{Conclusion}

The results of our activity are overwhelmingly positive in the sense of achieving a great level of motivation among the students in the English literature class. The use of escape room experiences is revealed as an appropriate method to incorporate students to the learning process and to create in them the need to know more about the topics dealt in the classroom. These positive results, however, should not distract educators and students from the fact that there are several constraints that may prevent the activity from being totally successful. First of all, online activities are prone to suffer interruptions due to powercuts or faulty internet connections. The improper use of computer devices such as cameras or microphones may also play their part in the lack of fluidity of the teaching process. Additional problems are presented by the density of academic programmes and sheer lack of time during a regular working week. Creating and implementing an engaging and attention-grabbing escape room for the students also implies a considerable investment of time on the part of educators and this time is usually taken in detriment of their personal lives. All in all, the benefits conveyed by the use of escape rooms in the English literature class may compensate for all the difficulties that are met along the way.

\section{References}

Abrams Schamroth, S. \& Walsh, S. (2014). Gamified Vocabulary. Journal of Adolescent \& Adult Literacy $581,49-58$.

Cronk, M. (2012). Using Gamification to Increase Student Engagement and Participation in Class Discussion. EdMedia+: Innovate Learning Association for the Advancement of Computing in Education (AACE), 311-315.

Deterding, S. (2012). Gamification: Designing for Motivation. Interactions, 19 4, 14-17.

Dorado Escribano, G. (2019). New approaches to learning and assessing through escape rooms in English and Science areas. Advances in Building Education, 3 1, 9-19.

Gómez Sesé, P. (2020). Escape Room. Todo lo que deberías saber sobre el mundo de los Escape Room. La guía definitiva. Wroclaw, Poland: Amazon Fulfillment.

Grouling, J., Hedge, S., Schweigert, A., \& Snider, E. G. (2014). Questing through Class: Gamification in the Professional Writing Classroom. Computer Games and Technical Communication: Critical Methods and Applications at the Intersection, 265-82.

Kato, T. (n.d.). Thoughts on Real Escape Game. Retrieved April 20, 2021, from https://realescapegame.com/thoughts-reg/

Kroski, E. (2019). Escape Rooms and Other Immersive Experiences in the Library. Chicago, US: Ala Editions.

Lázaro, A. (2019). Próximo Destino: Un Escape Room. April 20, 2021, from https://viajes.nationalgeographic.com.es/lifestyle/turismo-escape-room-espana_14701

Lee, J. J., \& Hammer, J. (2011). Gamification in education: What, How, Why Bother? Definitions and Uses. Exchange Organizational Behavior Teaching Journal, 15 2, 1-5.

López Secanell, I. \& Ortega Torres E. (2020). Escape room educativa: Concepción de los futuros maestros de Educación Secundaria en especialidad de Educación Física y Tecnología sobre la experiencia de diseñar y participar en una escape room educativa. Didacticae 8, 176-192.

Mazur, M., Rzepka, R. \& Araki, K. (2011). Proposal for a Conversational English Tutoring System that Encourages User Engagement. Proceedings of the 19th International Conference on Computers in Education, 10-12.

McGonigal, J. (2011). Reality is Broken: Why Games Make Us Better and How They Can Change the World. London: Penguin.

Moran, J. (2002). Interdisciplinarity. London: Routledge.

Nicholson, S. (2015). Peeking behind the locked door: A survey of escape room facilities. Scott Nicolson. April 22, 2021, from http://scottnicholson.com/pubs/erfacwhite.pdf

Santamaría, A., \& Alcalde, E. (2019). Escaping from the English Classroom. Who Will Get out First?. Aloma, 37(2), 83-92.

Stott, Andrew, and Carman Neustaedter. (2013). Analysis of Gamification in Education. Canada 8, 1-8.

Why Educational Escape Rooms Will Benefit Students in the Long Run (2017). April 20, 2021, from https://brainyactzsocal.com/educational-escape-rooms-will-benefit-students-longrun/\#: :text=Escape\%20rooms\%20are\%20innovative\%20learning,Learning\%20is\%20an\%20activ $\mathrm{e} \% 20$ sport.

Wong, R. (2014). Motivation to Learn English and School Grade Level. Porta Linguarum, 21, 37-50.

Wood, L. C., \& Reiners, T. (2012). Gamification in logistics and supply chain education: Extending active learning. In IADIS 2012 International Conference on Internet Technologies and Society, 101-108. 